\title{
Vidas precárias: tecnologias de governo e modos de gestão da fecundidade de mulheres "vulneráveis"
}

Precarious lives: government technologies and management modes of "vulnerable" women's fertility

\author{
Elaine Reis Brandão' \\ https://orcid.org/0000-0002-3682-6985 \\ brandao@iesc.ufrj.br \\ Cristiane da Silva Cabral" \\ https://orcid.org/0000-0003-3025-2404 \\ cabralcs@usp.br \\ ' Universidade Federal do Rio de Janeiro - Rio de Janeiro, RJ, Brasil \\ " Universidade de São Paulo - São Paulo, SP, Brasil
}




\title{
Resumo
}

Lacunas no planejamento reprodutivo, após 25 anos da Lei de Planejamento Familiar, no Brasil, têm promovido uma ressignificação do controle reprodutivo. As expressivas dificuldades para realização da laqueadura tubária no Sistema Único de Saúde têm permitido o florescimento de estratégias governamentais fomentando acesso estratificado e racializado a métodos contraceptivos reversíveis de longa duração (LARC). A pesquisa etnográfica apoiou-se em fontes documentais sobre iniciativas institucionais para inclusão de LARC no sistema público de saúde, tomando-se o município de São Paulo como caso empírico paradigmático. Envoltas no ideário da cidadania, argumenta-se que tais tecnologias de governo são acionadas na direção contrária à ampliação de direitos sexuais e reprodutivos, para reificar estereótipos sociais que subtraem a autonomia reprodutiva das mulheres. Tomando o conceito de "coerção contraceptiva" como categoria de análise, demonstra-se como tais expedientes ferem o paradigma da justiça reprodutiva no Brasil ao se institucionalizar a exclusão social pelo útero das mulheres "vulneráveis".

Palavras-chave: justiça reprodutiva; controle da fecundidade; contracepção reversível de longo prazo; biopolítica.

\begin{abstract}
Gaps in family planning, after 25 years of the Family Planning Law in Brazil, have promoted a resignification of fertility control. Difficulties in performing tubal ligation in the Unified Health System have allowed governmental stratified and racialized strategies of access to long-acting reversible contraceptive methods (LARC) to flourish. The ethnographic research relies on documentary sources on institutional initiatives for the inclusion of LARC in the public health system, taking the municipality of São Paulo as a paradigmatic empirical case. Apparently related to the ideology of citizenship, we argue that such technologies of government go into the opposite direction to the expansion of sexual and reproductive rights, reifying social stereotypes that subtract women's reproductive autonomy. Using the concept of "contraceptive coercion" as a category of analysis, we demonstrate how such strategies injure the reproductive justice paradigm, by institutionalizing social exclusion through the uterus of "vulnerable" women in Brazil.
\end{abstract}

Keywords: reproductive justice; fertility control; long-acting reversible contraception; biopolitics. 


\section{Fissuras no planejamento reprodutivo do Sistema Único de Saúde ${ }^{1}$}

A esterilização feminina ocupou por décadas o debate sobre regulação da fecundidade no Brasil. Juntamente com a pílula anticoncepcional, a laqueadura tubária sempre apresentou nas Pesquisas Nacionais de Demografia e Saúde (PNDS) - realizadas em 1986, 1996, 2006 - alta prevalência entre as mulheres, sendo, via de regra, sua escolha majoritária para controle da reprodução (Brasil, 2008). Todavia, a laqueadura tubária com fins contraceptivos somente foi legalizada no país no final da década de 1990, com a Lei do Planejamento Familiar (Brasil, 1996). Até então, a prática da laqueadura assentava-se fortemente num acordo privado entre mulheres e médicos, em que se negociava "um procedimento a mais" ou "complementar" na hora do parto que, por seu turno, invariavelmente era uma cesariana.

A lei torna a esterilização voluntária acessível no Sistema Único de Saúde (SUS) para

homens e mulheres com capacidade civil plena e maiores de 25 anos de idade, ou, pelo menos, dois filhos vivos, desde que observado o prazo mínimo de sessenta dias entre a manifestação da vontade e o ato cirúrgico, período no qual será propiciado à pessoa interessada acesso ao serviço de regulação da fecundidade, incluindo aconselhamento por equipe multidisciplinar, visando desencorajar a esterilização precoce. (Brasil, 1996).

Sem dúvida, era também uma forma de enfrentar o excesso de cesarianas realizadas no país de modo desnecessário e sem critérios clínicos precisos para sua indicação (Berquó, 1993).

Logo após os primeiros anos de sua promulgação, já se observava efeitos adversos dela decorrentes, e as controvérsias em torno da laqueadura tubária se seguiram. A referida lei, pensada enquanto forma de regular e democratizar o acesso a um procedimento altamente frequente no país, acabara restringindo-o: os serviços de saúde não seguiram o disposto pelas portarias

1 Agradecemos o apoio do CNPq (PQ 312316/2019-4). 
ministeriais; profissionais de saúde criaram regras próprias a partir de distintas interpretações da lei em que, por exemplo, a partícula "ou" (25 anos ou dois filhos vivos) era frequentemente compreendida como "e" (dupla exigência de idade mínima e número de filhos), sobretudo no caso de mulheres jovens; mantinha-se com força a representação de que " 25 anos" era "muito cedo" para se adotar a esterilização como método contraceptivo irreversível, e alguns serviços consideravam "30 anos" como a idade mínima para obtenção do procedimento (Berquó; Cavenaghi, 2003). Há também variações em torno do entendimento nos serviços sobre "registro de expressa manifestação da vontade em documento escrito e firmado, após a informação a respeito dos riscos da cirurgia" enquanto uma das condições para realização da esterilização. Outra barreira advém da necessidade de consentimento expresso de ambos os cônjuges "na vigência de sociedade conjugal" para sua obtenção. Além de se constituir em uma forma explícita de subordinar as decisões reprodutivas femininas à dimensão da conjugalidade, há registros de não concessão do procedimento a quem não conta com parceiro estável, apesar dos critérios acerca da idade ou do número de filhos serem suficientes nesses casos (Cabral, 2014).

Essas são algumas dimensões que nos fazem argumentar a respeito de um vácuo produzido pelos efeitos imprevistos da Lei do Planejamento Familiar no que se refere à regulação da reprodução. No cenário brasileiro, a laqueadura ocupava tradicionalmente um lugar de destaque na busca de meios seguros e eficazes para o encerramento da trajetória reprodutiva. Era também colocada enquanto "solução" altamente eficaz para controle das trajetórias reprodutivas de mulheres pertencentes a segmentos sociais "vulneráveis" da população, ou seja, com baixa escolaridade, baixa renda, com número grande de filhos, geralmente fruto de diferentes parcerias e tidos "sem planejamento" (Cavenaghi; Alves, 2019). Contudo, seu caráter de irreversibilidade sempre foi controverso: se, por um lado, a esterilização representava a oportunidade de encerrar a trajetória reprodutiva para as mulheres, por outro lado, o discurso sobre a possibilidade de arrependimento pós-esterilização era (e ainda é) frequentemente acionado pelos profissionais de saúde como justificativa para oposição à laqueadura (Cabral, 2014). Assim, não nos parece casual o atual cenário de forte defesa dos métodos contraceptivos reversíveis de longa duração (long-acting reversible contraception - LARC) por parte de organismos internacionais, 
instituições médicas e indústria farmacêutica. ${ }^{2}$ Afinal, são dispositivos que congregam diversos "benefícios" almejados por mulheres, médicos e Estado nos contraceptivos: altamente eficaz, dispensa a perícia da usuária e tem caráter reversível. Em outras palavras, as antigas e novas barreiras de acesso à laqueadura tubária no país produzem um cenário cada vez mais receptivo aos métodos LARC enquanto opção contraceptiva, sobretudo para as mulheres em situação de "vulnerabilidade". É sobre esta segunda parte da equação que o artigo se debruça, pois é nela que se processam subtrações em termos de direitos reprodutivos e institucionalização de novas formas de tutela e controle da vida reprodutiva das mulheres pelo Estado.

\section{Governança reprodutiva: ressignificando o controle reprodutivo}

O debate sobre governança reprodutiva no plano internacional nos convida a pensar sobre a pertinência de tal acepção para o Brasil, a partir do exemplo concreto das políticas públicas de saúde relativas ao planejamento reprodutivo. Assim, elegemos alguns tópicos para discussão dentro desse arcabouço teórico-político que iluminam a análise aqui proposta sobre as formas atuais de controle reprodutivo via métodos contraceptivos reversíveis de longa duração. No primeiro momento, abordamos as noções de "governança reprodutiva" (Morgan, 2019; Morgan; Roberts, 2012), "populacionismos" (Bhatia et al., 2020; Hendrixson, 2019; Hendrixson et al., 2020;) e "coerção contraceptiva" (Senderowicz, 2019), em estreita articulação com os dispositivos de sexualidade (Foucault, 1999) e de racialidade (Carneiro, 2005), para emoldurar as inquietações teóricas pertinentes ao objeto em estudo. Em seguida, centramo-nos nas expressivas dificuldades que cercam a contracepção na vida das mulheres, como um ato relacional e permeado pela hierarquia de gênero, para situar como os métodos LARC vêm ocupando um espaço precioso nos processos crescentes de biomedicalização (Clarke et al., 2003, 2010; Clarke; Shim, 2011) da vida em aliança com o pragmatismo neoliberal.

2 Como esclarecer-se-á adiante, os métodos LARC compreendem dispositivos intrauterinos e implantes subdérmicos hormonais. 
O conceito de governança reprodutiva não é novo, assim como as conexões entre raça, classe social, reprodução, sexualidade e saúde também não o são. Nosso desafio é elucidar as formas contemporâneas que tais estratégias sociotécnicas e políticas assumem em estreita porosidade com o discurso dos direitos humanos. Captar certa racionalidade tecnocrática que preside muitas propostas de "planejamento familiar" ou reprodutivo, suas lógicas subjacentes, os valores e práticas sociais por elas desencadeadas nos ajudará na reflexão crítica sobre um tema tão espinhoso quanto a relação entre população e desenvolvimento.

Morgan e Roberts (2012, p. 243) designam como governança reprodutiva

the mechanisms through which different historical configurations of actors such as state institutions, churches, donor agencies, and non-governmental organisations (NGOs) - use legislative controls, economic inducements, moral injunctions, direct coercion, and ethical incitements to produce, monitor and control reproductive behaviours and practices. ${ }^{3}$

Recuperando conceitos caros a esse campo de discussão como "reprodução estratificada", ou seja, acesso desigual e estratificado a condições sociais estruturais para se reproduzir, elas destacam as intricadas relações entre movimentos mais amplos, em nível global, que rearticulam interesses financeiros, hegemonias políticas, imperialismos coloniais, ativismos sociais e tecnologias biomédicas na direção de um bem-estar global que se consubstanciam de modo difuso, intersticial em práticas políticas locais, as quais consolidam "regimes morais de reprodução". Desse modo, as autoras nos ajudam a complexificar os sentidos que atravessam as múltiplas tecnologias de reprodução como formas de pensar o gênero, a dimensão étnico-racial e de governar os corpos.

Em um cenário de intensificação dos processos de biomedicalização (Clarke et al., 2003, 2010; Clarke; Shim, 2011) ou de farmacologização da vida (Collin, 2016; Williams; Martin; Gabe, 2011), as conexões entre biotecnologias, mercado

3 No texto mais recente, Morgan (2019, p. 113) reescreve a definição anterior: “[...] refers to the mechanisms through which different historical configuration of actors - such as state, religious, and international financial institutions, NGOs, and social movements - use legislative controls, economic inducements, moral injunctions, direct coercion, and ethical incitements to produce, monitor, and control reproductive behaviors and population practices". 
de capitais, desigualdades socioeconômicas entre países do norte e do sul, disputas geopolíticas, filantropia empresarial e humanitarismo tornam as questões relativas ao debate populacional um solo fértil para o ativismo/marketing social sobre o campo da reprodução em países pobres.

Reunindo um conjunto amplo de trabalhos críticos em torno de grandes e celebrados projetos transnacionais sobre planejamento reprodutivo na última década, que tem nos métodos LARC a principal estratégia de intervenção, ${ }^{4}$ Hendrixson e colegas (Bendix et al., 2020; Bhatia et al., 2020; Hendrixson, 2019; Hendrixson et al., 2020) decodificam as novas formas de acionamento do controle populacional, bem mais sofisticadas e sutis, articuladas ao ideário dos direitos sexuais e reprodutivos e às metas de cumprimento dos objetivos do desenvolvimento sustentável (ODS) no âmbito da Organização das Nações Unidas. Em um conjunto sólido de trabalhos, as estratégias de difusão de métodos contraceptivos de longa duração, considerados a "primeira linha" entre os métodos disponíveis, acabam por acentuar novas sujeições e subordinações das mulheres "beneficiárias" de tais programas, residentes em países pobres. As autoras chamam de "populacionismos" um conjunto de intervenções que mantém a premissa central de que os problemas sociais e ambientais são decorrentes do crescimento populacional. Analisam uma importante network designada Family Planning 2020 (FP2020), um conjunto de parcerias público-privadas que buscam cumprir metas geográficas, biopolíticas e ambientais na direção do controle reprodutivo. Elas criticam intervenções microssocietárias (precisamente no corpo das mulheres negras e pobres), através do incentivo aos métodos LARC, para redução do contingente populacional, com vistas a preservar

4 As autoras se dedicaram a examinar a iniciativa Family Planning 2020 (FP2020), estabelecida na Cúpula de Londres sobre o Planejamento Familiar, em 2012, com o slogan "120 by 20", ou seja, buscava-se alcançar 120 milhões de novas usuárias de métodos contraceptivos modernos (LARC) nos 69 países pobres participantes (41 deles na África) até o ano de 2020, sempre promovidos por um consórcio de instituições, a exemplo do Departamento de Desenvolvimento Internacional do Reino Unido, Agência dos Estados Unidos para o Desenvolvimento, Fundo de População das Nações Unidas, Fundação Bill e Melinda Gates, dentre outras. O Implant Access Program (IAP) foi analisado, com destaque para os implantes Implanon ${ }^{\circledR}$, Implanon NXT ${ }^{\circledR} \mathrm{e}$ Jadelle ${ }^{\circledR}$, este último uma versão renovada do Norplant, além do injetável trimestral Sayana ${ }^{\circledR}$ Press, também uma versão de segunda geração do Depo-Provera, ambos contraceptivos envoltos em controvérsias. Como comenta Hendrixson (2019, p. 789): “Thus, the ' 120 by 20' target is racialized and gendered, as well as geographically placed." Para mais informações sobre a iniciativa FP2020, cf. http://www.familyplanning2020.org/. 
espaços geográficos ambientalmente sustentáveis, mediante controle dos deslocamentos populacionais e por meio do uso de tecnologias biomédicas.

A complexidade que subjaz a tal iniciativa (FP2020) nos impõe cautela, pois os princípios que a sustentam se coadunam ao ideário erigido na Conferência Internacional sobre População e Desenvolvimento, no Cairo, Egito, em 1994, rejeitando o controle populacional e atestando a dimensão voluntária do planejamento familiar, sua filiação à defesa dos direitos humanos, ao empoderamento feminino e aos direitos reprodutivos. A iniciativa mobiliza a transferência de recursos, incentivos fiscais, treinamentos de profissionais de saúde, conhecimentos científicos por meio de pesquisas clínicas, demográficas, com vistas ao cumprimento das metas previstas. Todavia, em diversos contextos a atenção à saúde das mulheres se reduz a aceitar a inserção de um dispositivo LARC como medida de "proteção" à saúde e de engajamento em um script tecnocientífico moderno - esse parece ser também o caso do Brasil, tal como veremos adiante.

Debruçando-se sobre a mesma iniciativa (FP2020), em pesquisa etnográfica desenvolvida em país da África Subsaariana, outra autora nos traz uma chave de análise preciosa para compreender processos de trabalho nas instituições de saúde relativos ao aconselhamento contraceptivo. Buscando desvendar a genealogia do termo "coerção contraceptiva" em programas de planejamento familiar, Senderowicz (2019) evidencia a sofisticação que tal categoria pode adquirir distanciando-se de uma concepção simplista que a equipara a um ato violento de alguém contra outra pessoa. Ao contrário, amparada no paradigma da justiça reprodutiva (Price, 2010; Roberts, 2015; Ross, 2017), a autora sinaliza para uma dimensão bem mais oculta que integra processos estruturais macrossocietários relativos aos sistemas de saúde e agentes do Estado - que se consubstancializam em quotas, metas, indicadores, custos, cálculos e estimativas - mediados por intervenções e ações individuais, aparentemente neutras, técnicas.

A autora destaca a dupla direcionalidade que a coerção contraceptiva pode adquirir, desde a obrigação/força para a aceitação de determinado método contraceptivo que a mulher não quer, até ser impedida ou ter dificuldades para acessar métodos que elas desejam, comumente conhecidas como "barreiras de acesso" ou "provider bias", tais como as estigmatizações sofridas por adolescentes e jovens, não casadas/unidas, em relação ao exercício de sua sexualidade. 
Sua análise demonstra uma gradação de práticas institucionais nos serviços de saúde que comumente não costumamos tomar como coercitivas, mas que obstaculizam a autonomia reprodutiva feminina, tal como a oferta restrita de métodos contraceptivos que não contempla as necessidades das mulheres em diferentes contextos relacionais, socioculturais, geracionais.

Segundo a autora, há um espectro na abordagem à coerção que vai desde a dimensão estrutural até a interpessoal. Senderowicz (2019) aborda entraves à autonomia reprodutiva de mulheres atendidas em programas de planejamento familiar, as quais relatam diversos constrangimentos para a escolha e adoção de métodos contraceptivos. Ela exemplifica tal espectro de coerção: informações médicas parciais (explicitação de vantagens do método e não de seus efeitos colaterais), aconselhamentos enviesados ou dirigidos, limitado conjunto de métodos disponíveis, insistências até que as mulheres aceitem tal ou qual método, ameaças de restrição na atenção futura à saúde, inserção de métodos sem o conhecimento ou consentimento da mulher, em especial no período pós-parto, recusa de remoção de métodos LARC sob pedido da usuária, antes do tempo previsto para sua expiração, dentre outros.

Em suma, o fenômeno da coerção contraceptiva se imiscui em um esquema mais amplo relativo às formas como os programas de planejamento familiar e serviços de saúde são organizados, por meio de incentivos fiscais, aportes de recursos internacionais, metas a cumprir, dentre outras modalidades de apoio, que terminam por subordinar a autonomia reprodutiva como um princípio basilar desses programas.

\section{A centralidade da long-acting reversible contraception na gramática dos direitos}

Tendo em vista a enorme complexidade que permeia relações sociais entre parceiros heterossexuais para decisões contraceptivas, mediadas por constrangimentos estruturais, culturais, de gênero, raciais e geracionais, as descontinuidades contraceptivas são processos contingentes à vida das mulheres (Borges et al., 2021). Escolher e incorporar o uso de algum método contraceptivo na vida cotidiana não é uma decisão simples, nem técnica, mas envolve a relação da mulher com seu corpo, suas condições de saúde, seu parceiro, seu 
momento de vida, existência de filhos, os profissionais de saúde e serviços que as acolhem, efeitos colaterais dos métodos hormonais, entre outros aspectos importantes. Sem mencionar a violência sexual presente em muitos contextos relacionais. Quando não se tem compreensão da inextricabilidade da contracepção em relação ao gênero, à sexualidade e à saúde, toma-se a gravidez imprevista como algo que denota um fracasso das mulheres, um atestado de sua incompetência na gestão de sua fecundidade. Tendo em vista que os métodos contraceptivos de barreira (preservativos masculino e feminino, diafragma) não são amplamente usados e os métodos hormonais de curta duração (pílulas anticoncepcionais, injetáveis mensais ou trimestrais) exigem regularidade no uso cotidiano ou mensal, os métodos de longa duração têm adquirido cada vez mais destaque nos meios científicos médico, demográfico, político, sendo promovidos com intensa euforia por empresas farmacêuticas, agências multilaterais, organizações não governamentais e instituições filantrópicas como resposta eficaz ao problema do controle reprodutivo, sobretudo entre mulheres pobres do mundo todo.

A construção social desse grupo de métodos contraceptivos reversíveis de longa duração como algo de excelência irrefutável condensa duas dimensões estratégicas: sua consagração entre profissionais e associações médicas internacionais baseada nas chamadas "evidências científicas", que ressaltam sua eficácia, segurança e relação custo-benefício em diversos guidelines (American Association of Pediatrics, 2014; Federação Brasileira das Associações de Ginecologia e Obstetrícia, 2016; Ponce de Leon et al., 2019; World Health Organization, 2012), e sua associação simbólica com valores éticos ocidentais relativos à autonomia e ao empoderamento feminino. ${ }^{5}$ Ao retirar da contracepção sua dimensão relacional, conectada às relações de gênero e ao exercício da sexualidade, para torná-la um ato estritamente médico e individual, cria-se um fetiche em torno dessas tecnologias biomédicas, apresentadas como solução ou resposta ideal para o controle reprodutivo de todas as mulheres, independentemente dos contextos culturais, socioeconômicos, políticos nos quais constroem sua existência.

5 Tal como expressam Brian, Grzanka e Mann (2020, p. 5): "LARC is not just a birth control but a technological life hack for health and happiness." 
Amparada em indicadores de saúde que apontam taxas de mortalidade e morbidade maternas e infantis preocupantes, gravidezes não planejadas, abortos inseguros e consequentemente custos em atenção à saúde para o enfrentamento de tais problemas, a equação simplista de promoção dos métodos LARC ofusca as inequidades sociais existentes nos sistemas de saúde e os constrangimentos estruturais que impedem que as mulheres possam ter acesso a melhores condições de vida, incluindo direito à educação, proteção social, habitação, trabalho e renda, não violência, entre outros aspectos fundamentais para a dignidade humana.

A difusão dos métodos LARC tem sido extremamente bem-sucedida também em razão de um contexto de crescente responsabilização dos sujeitos por sua saúde, isentando o Estado desses cuidados, em consonância a uma ótica neoliberal. O chamado healthism (Crawford, 1980) aborda essa tendência de culpabilização dos indivíduos por comportamentos, estilos de vida ou atitudes que contrariam as normas sanitárias que preconizam o bem-estar e a saúde como valores modernos a serem alcançados. Maximizar a saúde passa a ser uma obrigação moral nessa perspectiva. No campo da sexualidade e da reprodução, as dimensões de autocontrole e de responsabilização tornam-se estratégicas ao serem entronizadas na formulação de "direitos sexuais", como assinala Carrara (2015) ao discutir as políticas sexuais no Brasil e seus peculiares estilos de regulação moral.

Ao apontar a apropriação e subordinação da dimensão da sexualidade pela saúde, condensada na expressão "saúde sexual" tão propalada pelas agências internacionais, Epstein e Mamo (2017) elaboraram a categoria de "sexual healthism" para evidenciar as formas de responsabilização moral dos sujeitos por suas práticas sexuais e, no nosso caso, pela não proteção à gravidez. Detendo-se no exame das políticas de inserção dos métodos LARC no pós-parto imediato, desde 2012, nos Estados Unidos da América, Brian, Grzanka e Mann (2020) ressaltam que o discurso da cidadania sexual foi paradoxalmente reduzido ao acesso a uma única classe de tecnologias contraceptivas. Filiando-se aos estudos sociais da ciência e da tecnologia, eles advogam a dupla dimensão das campanhas de saúde pública que promovem tais dispositivos: se por um lado expressam mecanismos coercitivos inerentes à governança reprodutiva (Takeshita, 2012), por outro produzem cidadãs sexualmente responsáveis, adeptas ao ideário normativo neoliberal da boa saúde, ao contrário 
daquelas mulheres consideradas irresponsáveis, irracionais, que fracassam na regulação de sua fecundidade, majoritariamente, mulheres pobres, negras, latinas, migrantes, dentre outras. Como afirmam os autores (Brian; Grzanka; Mann, 2020, p. 4): "Thus, the neoliberalization of sexual health promotion frames personal responsibilization as inherently empowering, even as its effects are punitive. [...] Sexual citizenship, healthism, and technoscience collide in LARC's fraught global trajectories."

Abordagens críticas à panaceia que se criou em torno dos métodos LARC como resposta única para controle da reprodução entre adolescentes e jovens têm sido publicadas por pesquisadoras feministas engajadas na defesa do paradigma da justiça reprodutiva (Brian; Grzanka; Mann, 2020; Gomez; Fuentes; Allina, 2014; Gubrium et al., 2016; Higgins, 2014). Defendendo uma abordagem compreensiva da sexualidade e um framework centrado nas mulheres, em suas necessidades específicas conforme suas trajetórias de vida, tais pesquisadoras denunciam o racismo subjacente a tais práticas, discordando da alternativa pragmática de que os métodos LARC sejam a opção mais adequada/favorável indistintamente a toda e qualquer mulher. ${ }^{6}$

Em nosso contexto, a não implementação da política pública existente para acesso das mulheres usuárias do SUS à laqueadura tubária ganha sentido, ao se promover em seu lugar dispositivos biomédicos para contracepção, de custos expressivos, ${ }^{7}$ em um processo que os autores acima citados designam como "technoscientific healthism" (Brian; Grzanka; Mann, 2020).

Assim, neste trabalho, buscamos examinar detidamente um conjunto de iniciativas engendradas pelo município de São Paulo, nos últimos cinco anos, na direção da institucionalização da oferta de métodos contraceptivos reversíveis

6 A pandemia da Covid-19 desencadeou uma aceleração ainda maior da estratégia internacional de adoção dos métodos LARC em países periféricos em razão das dificuldades de abastecimento de métodos contraceptivos tradicionais, de acesso aos serviços de saúde para atenção em saúde reprodutiva, terminando por dar um impulso às intervenções humanitárias com essa feição. Esse assunto não será tratado neste artigo, mas merece certamente atenção como um efeito não previsto da pandemia que se articulou às diretrizes de expansão desta modalidade de contraceptivos no mundo.

7 No mercado farmacêutico, os preços para compra no varejo pela consumidora de dispositivos LARC (DIU ou implante subdérmico) giram em torno de aproximadamente R\$ 1.000,00 a $R \$ 1.500,00$ cada unidade, mas a aquisição desses produtos frequentemente é mediada por profissionais médicos ou clínicas médicas, com custos maiores, pois a inserção deve ser feita por especialista treinado. 
de longa duração a mulheres "vulneráveis". Ao não se enfrentar a discussão mais ampla sobre a necessária abordagem da sexualidade, do gênero e da violência sexual nas políticas públicas de educação e de saúde, o acesso universal ao planejamento reprodutivo, com disponibilidade de variado leque de métodos contraceptivos às mulheres, em diferentes fases da vida, toma-se $o$ atalho da oferta "seletiva" de LARC a certos perfis de mulheres (Brandão; Cabral, 2021), paradoxalmente amparada na gramática dos direitos e do empoderamento feminino, denotando assim, nova roupagem do controle reprodutivo no país.

\section{Procedimentos metodológicos}

A pesquisa antropológica que subsidia este artigo se inspira em uma tradição de estudos documentais, de caráter etnográfico, que vem se consolidando no Brasil, nas últimas décadas (Ferreira; Lowenkron, 2020; Fonseca et al., 2016; Lowenkron; Ferreira, 2014; Vianna, 2014) sobre modos de administração pública de processos sociais relativos ao viver, adoecer, morrer, conectados à perspectiva de se perscrutar os interstícios do "duplo fazer" de gênero e do Estado (Vianna; Lowenkron, 2017). Essa via da coprodução do gênero e do Estado, por meio da regulação da sexualidade e da reprodução entre mulheres, tem sido também explorada por Corossacz (2009), Dalsgaard (2006), Faya-Robles (2015) e Fernandes (2019a, 2019b), em sua incursão etnográfica no Rio de Janeiro, nos morros da Mineira e do São Carlos, em torno das categorias "novinhas", "mães nervosas" e "mães abandonantes", presentes no discurso popular.

Observando os modos de gestão pública da regulação da fecundidade das mulheres, redesenhados pelo repertório ético-político advindo da Conferência Internacional sobre População e Desenvolvimento, no Cairo, Egito, em 1994, e pela IV Conferência Mundial sobre a Mulher, em Pequim, na China, em 1995, que instituem o paradigma dos direitos sexuais e reprodutivos (Carrara; Vianna, 2008; Corrêa; Petchesky, 1996), notamos na atualidade a reinstauração de formas de governo da vida que reintroduzem mecanismos coercitivos à reprodução, paradoxalmente articulados ao idioma dos direitos humanos. Seguindo pistas deixadas por documentos oficiais, tais como legislações, protocolos clínicos, notas técnicas, produzidos para orientação da atuação de profissionais de saúde nos serviços públicos, pretendemos evidenciar como tais 
artefatos documentais criam materialidades, moralidades e produzem "novos" sujeitos, pela via periférica do acesso à cidadania mediada pelo útero. A singularidade da análise reside, portanto, no esforço de captar nas entrelinhas dos documentos as intenções que subjazem às normativas técnicas, forjadas em consonância ao paradigma dos direitos reprodutivos que terminam por reificar discriminações e estigmas.

Como reatualização da biopolítica, em tempos de crescente biomedicalização dos processos de atenção e cuidado à saúde, a perspectiva teórica da governança reprodutiva nos ajuda a compreender que tais iniciativas não são meramente circunstanciais nem localizadas, mas integram um movimento muito mais amplo, internacional, que congrega uma rearticulação de forças políticas, científicas, econômicas, de cariz neoliberal, que buscam redefinir as políticas populacionais em especial no Sul global, catalisando o discurso ambientalista e de empoderamento feminino, no intuito de redução da fecundidade das mulheres, não propriamente como um ato voluntário, mas prioritariamente como um indicador demográfico culturalmente imposto pelas agências multilaterais, reiterando novas colonialidades.

Este trabalho advém da pesquisa "Direitos sexuais e reprodutivos em debate: desvendando sentidos e usos sociais de dispositivos biomédicos para contracepção e esterilização em mulheres", ${ }^{8}$ cujas fontes documentais são de acesso público, disponíveis no ciberespaço. Na primeira fase da pesquisa, nos últimos dois anos, vimos compilando notícias veiculadas na mídia eletrônica a respeito da circulação dos dispositivos LARC no Brasil e reunindo material empírico, como documentos legais e institucionais (projetos de lei, decretos, protocolos, etc.), que informam sobre a disponibilidade de tais dispositivos na

8 Além dos métodos contraceptivos reversíveis de longa duração, hormonais, que serão tratados neste artigo, a pesquisa também compreende outro dispositivo biomédico para esterilização, chamado Essure ${ }^{\circledR}$, que circulou no Brasil entre 2009 e 2017, tendo sido retirado do mercado internacional pela empresa farmacêutica Bayer em setembro de 2017 e, posteriormente, em dezembro de 2018, dos Estados Unidos, encerrando a comercialização do produto. No entanto, a vida social desse artefato técnico continua por meio do ativismo social das mulheres que o tiveram implantado e hoje lutam pela retirada do dispositivo de seus corpos em razão dos muitos problemas de saúde dele decorrentes (gravidez, dor crônica, cólicas abdominais, sangramentos, desconforto pélvico, perfuração de trompas ou útero, migração do dispositivo das trompas para outras partes do corpo, alergia e diversos sintomas sugestivos de sensibilidade e reações imunológicas associadas ao níquel, usado em sua fabricação). Para mais detalhes, cf. Brandão e Pimentel (2020). 
rede pública de saúde do país e as condições sociais nas quais são ofertados, position papers emitidos pela sociedade civil organizada, associações médicas, bem como vasta documentação internacional a respeito produzida por agências como Organização Mundial da Saúde, Fundo de População das Nações Unidas, dentre outras. ${ }^{9}$ Em um segundo momento, pretende-se ouvir mulheres usuárias desses métodos contraceptivos sobre tal experiência, para conhecermos melhor como tem sido sua participação nesses programas.

Embora os métodos LARC estejam sendo promovidos em diversos estados e municípios do país, de norte a sul (Brandão; Cabral, 2021), neste trabalho elegemos o município de São Paulo como caso empírico paradigmático para desenvolver nosso argumento acerca do que designamos uma "oferta seletiva" desses métodos a mulheres consideradas pelo aparato público governamental como "vulneráveis". A escolha dessa metrópole se justifica por haver uma relativa continuidade político-partidária na gestão do município em anos recentes; a capital é também reconhecida por ter uma sólida e organizada rede de assistência à saúde, com contínua oferta de treinamento a seus profissionais. Não há dúvidas de que o maior município do país esteja sob permanente observação de outras cidades brasileiras e que determinadas iniciativas podem ser tomadas como modelo por elas. ${ }^{10}$

O único dispositivo reversível de longa duração ofertado pelo Sistema Único de Saúde no Brasil é o dispositivo intrauterino (DIU) de cobre. ${ }^{11}$ Pouco utilizado no país em razão de controvérsias que cercam os dispositivos intrauterinos no senso comum (prevalência de apenas $2 \%$ na PNDS 2006), eles foram recentemente promovidos em razão de uma portaria do Ministério da Saúde, de 2017,

9 Em termos práticos, a criação de "alertas" de publicação, a partir da seleção de categorias específicas (como LARC, por exemplo), em portais como Google, é uma estratégia que auxilia no monitoramento sistemático de notícias e demais conteúdos veiculados na internet sobre o tema.

10 Em outro momento histórico e sociopolítico, o município de São Paulo foi um dos pioneiros do país a implantar o serviço de aborto legal às mulheres vítimas de violência sexual, garantindo um direito assegurado no Código Penal, desde 1940, em estreita articulação com o movimento feminista e com profissionais de saúde comprometidas com o ideário da Reforma Sanitária, em curso no país na década de 1980, e com os princípios do Programa de Assistência Integral à Saúde da Mulher (PAISM), elaborado em 1983, no âmbito do Ministério da Saúde.

11 Atualmente, o SUS deveria disponibilizar os métodos hormonais (pílula oral combinada, minipílula, pílula de emergência, injetável mensal e trimestral), de barreira (diafragma e preservativos masculino e feminino) e intrauterino (dispositivo com cobre), embora nem todos sejam facilmente encontrados nos serviços de saúde. 
que passou a autorizar e incentivar a inserção do DIU de cobre para anticoncepção pós-parto ou pós-abortamento imediatos nas maternidades públicas (Brasil, 2017). Tal iniciativa não ocorre de modo aleatório; ao contrário, está estreitamente correlacionada aos esforços mais amplos das agências multilaterais na direção de promoção de políticas de incentivo ao uso de métodos LARC no pós-parto imediato (Brian; Grzanka; Mann, 2020). No entanto, ainda não existem entre nós estudos publicados a respeito, sugerindo outra via fecunda de pesquisa. Precisamos também conhecer o desdobramento prático no cotidiano das maternidades dessa portaria, distinguir sob quais circunstâncias materiais e simbólicas eles são ofertados, as condições estruturais e subjetivas que ensejam tal aconselhamento no pós-parto ou pós-abortamento imediatos. Ainda não foram produzidas informações sistemáticas sobre se há ou não compulsoriedade nessas iniciativas, se as mulheres estão sendo respeitadas em suas "escolhas" contraceptivas, se são devidamente informadas, e como tais dimensões fazem interface com o cumprimento burocrático de metas institucionais de cobertura que respondem a outros interesses políticos e financeiros.

Os outros métodos LARC são hormonais, mas ainda não estão disponíveis de forma ampla e universal a todas as mulheres no SUS. No mercado farmacêutico internacional, existem muitos produtos sob a forma de implantes subdérmicos ou sistemas intrauterinos. No Brasil, estamos nos referindo ao implante subdérmico liberador de etonogestrel (conhecido como Implanon ${ }^{\circledR}$ ), com duração de três anos, e o sistema intrauterino com levonorgestrel (conhecido como DIU Mirena ${ }^{\circledR}$ ), com duração de cinco anos. ${ }^{12}$ Eles estão em circulação no país nas clínicas privadas ou consultórios ginecológicos há aproximadamente 20 anos; todavia identificamos sua entrada na rede pública de saúde nos últimos dez anos (nosso primeiro registro advém de matéria no Diário do Nordeste em $2010^{13}$ ), e sempre direcionados ao mesmo público, ou seja, adolescentes ou mulheres "vulneráveis".

No ano de 2015, a Federação Brasileira das Associações de Ginecologia e Obstetrícia (Febrasgo) solicitou ao Ministério da Saúde (MS) a incorporação

12 Coincidentemente com a pandemia da Covid-19, em 28 de maio de 2020, houve uma live restrita a profissionais médicos para lançamento no Brasil de um novo sistema intrauterino com levonorgestrel, fabricado pela Bayer, designado Kyleena ${ }^{\circledR}$, com duração de cinco anos, cuja divulgação enfatizava sua menor dimensão (em comparação ao Mirena ${ }^{\circledR}$ ) e "menor dosagem hormonal do mercado brasileiro" (19,5 mg comparados a $52 \mathrm{mg}$ no Mirena $\left.{ }^{\circledR}\right)$.

13 Cf. CE é o $1^{\circ}$ do Brasil... (2010). 
dessas tecnologias contraceptivas no SUS com indicações para uso em mulheres jovens de 15 a 19 anos. Em suas publicações (Federação Brasileira das Associações de Ginecologia e Obstetrícia, 2016; Penna; Brito, 2015), tal indicação menciona "populações especiais" ou "grupos vulneráveis" como beneficiários dessas tecnologias, sendo esses compreendidos como adolescentes, usuárias de drogas ilícitas, mulheres convivendo com vírus da imunodeficiência humana (HIV), "moradoras de rua”, "população de baixo nível socioeconômico". Após consulta pública feita pela Comissão Nacional de Incorporação de Tecnologias no SUS (Conitec), o MS negou tal pleito em 2016 (Brandão, 2019). Pelo que observamos, no entanto, a não incorporação desses métodos LARC no SUS de forma universal não tem impedido que gestores municipais ou estaduais, de forma descentralizada, decidam pela aquisição e distribuição em suas respectivas redes de serviços de saúde, sempre com oferta orientada para grupos específicos de mulheres. ${ }^{14}$

Percorremos na análise empreendida uma série de documentos que perfazem um conjunto de atos legais institucionais que ensejam uma nova "normalidade": a redução dramática da atenção à saúde reprodutiva das mulheres na direção de uma política de inserção de LARC dirigida àquelas tidas como inaptas no controle de sua fecundidade. Nesse sentido, o conceito de "coerção contraceptiva" (Senderowicz, 2019) nos auxilia a deslindar a sujeição sistemática de mulheres jovens, negras, pobres, em situação de exclusão social a mecanismos de tutela do aparato estatal, de cariz racista e eugênico, que acirram a desigualdade social e infringem de maneira inadmissível e violenta a dignidade e integridade corporal dessas mulheres.

14 Após submissão deste artigo para publicação, uma nova consulta pública $\mathrm{n}^{\circ}$ 01/2021 foi aberta à sociedade brasileira pela Comissão Nacional de Incorporação de Tecnologias no SUS (Conitec), em janeiro de 2021, para inclusão do implante subdérmico com etonogestrel para mulheres entre 18 e 49 anos no SUS, a pedido da empresa Schering-Plough Indústria Farmacêutica Ltda./ MSD. A decisão final foi favorável dessa vez, e publicada em Portaria SCTIE/MS nº 13, de 19 de abril de 2021, a qual: "Torna pública a decisão de incorporar o implante subdérmico de etonogestrel, condicionada à criação de programa específico, na prevenção da gravidez não planejada para mulheres em idade fértil: em situação de rua; com HIV/AIDS em uso de dolutegravir; em uso de talidomida; privadas de liberdade; trabalhadoras do sexo; e em tratamento de tuberculose em uso de aminoglicosídeos, no âmbito do Sistema Único de Saúde - SUS" (Brasil, 2021). Infelizmente, esse novo fato não poderá ser objeto de análise neste momento, por demandar uma discussão que extrapola os limites deste manuscrito, mas comprova a tese de expansão dos LARC no país de modo seletivo. 


\section{Tecnologias de governo: gestão da fecundidade em mulheres "vulneráveis"}

Como dito, percebemos uma inflexão nos últimos anos nas políticas públicas de saúde voltadas ao planejamento reprodutivo, à atenção à saúde sexual e reprodutiva na direção do estímulo à adoção dos métodos LARC para os chamados grupos de mulheres "vulneráveis" - que frequentemente englobam adolescentes, mulheres em situação de rua, usuárias de drogas, mulheres HIV positivas. Algumas iniciativas do município de São Paulo podem iluminar nosso argumento. Vejamos detidamente um conjunto de documentos legislativos ou do Poder Executivo que estabelecem tais diretrizes, bem como alguns protocolos que organizam e orientam as práticas de profissionais de saúde na incorporação dos métodos LARC no âmbito da Secretaria Municipal da Saúde. Primeiramente, eles regulam o uso do implante subdérmico de etonogestrel com duração de três anos em sua ação contraceptiva. ${ }^{15}$ Em um segundo momento, mais recente, eles compreendem a inclusão do Sistema Intrauterino com levonorgestrel (SIU-LNG), cuja ação contraceptiva dura cinco anos. Nesse sentido, o conjunto de saberes e práticas em torno dos LARC se constituem ferramentas privilegiadas para intervenção social, o que designamos como tecnologias de governo para regulação da fecundidade das mulheres.

\section{Institucionalização da oferta "seletiva" de LARC}

Leis, protocolos clínicos, decretos municipais, portarias compõem o rol de iniciativas governamentais para a institucionalização da oferta de LARC a determinados segmentos populacionais. Uma breve retrospectiva para o município de São Paulo pode ser remontada a 2015, quando a vereadora Patricia Bezerra (PSDB) apresentou o Projeto de Lei $n^{\circ} 467 / 2015$ sobre o tema (São Paulo, 2015). Aprovado em dezembro de 2017, na Câmara Municipal, e sancionado em 19 de

15 A promoção dos implantes contraceptivos na capital tem estado também presente em iniciativas no âmbito da Secretaria de Estado da Saúde de São Paulo, desde 2014, como o Projeto Gravius, voltado a usuárias de drogas, cujo coordenador é médico integrante da Comissão de Anticoncepção da Febrasgo e consultor dos laboratórios Bayer, Abbott, Genon e MSD (Nascimento, 2020). Como restringimos a análise à gestão municipal, não nos deteremos nesse projeto, que sem dúvida, tem fomentado os métodos LARC no estado. 
janeiro de 2018, deu origem à nova lei municipal n ${ }^{\circ} 16.806 / 2018$, que "dispõe sobre política de proteção às mulheres em situação de vulnerabilidade pela Rede Pública de Saúde, com a utilização do Contraceptivo Reversível de Longa Duração de Etonogestrel [implante subdérmico], e dá outras providências" (São Paulo, 2018a). Tal como publicado pela Câmara Municipal de São Paulo (Agora..., 2018), "o objetivo é reduzir tanto o número de gestações não planejadas como também diminuir a taxa de mortalidade infantil e materna. Dependentes químicas, moradoras de rua e adolescentes terão prioridade na distribuição gratuita, tanto na rede pública convencional [como] por meio de instituições conveniadas." O grupo de mulheres destinatárias estava assim descrito no texto da lei: "Populações especiais que fazem parte de algum grupo de risco, como adolescentes, usuárias de drogas ilícitas, mulheres convivendo com vírus da imunodeficiência humana, dentre outras" (São Paulo, 2018a).

Nesse ínterim, a Secretaria Municipal da Saúde de São Paulo havia anunciado em fevereiro de 2016, no âmbito de um projeto-piloto em um hospital maternidade municipal, a compra de mil implantes contraceptivos para ampliar a distribuição na rede de saúde, com a justificativa da economia que tais dispositivos poderiam acarretar:

Estima-se que a prefeitura economizará de $\mathrm{R} \$ 73.250$ a $\mathrm{R} \$ \mathbf{\$} 646.500$ apenas com gastos diretos hospitalares para cada mil implantes inseridos, considerando o custo estimado de uma gestação não planejada de R\$ 2.293,00. Esse valor considera apenas gastos com assistência hospitalar relacionados ao parto, nascimento e às complicações. $\mathrm{O}$ valor não considera gastos de saúde ambulatoriais como, por exemplo, consultas de rotina, vacinação e medicamentos, nem outros encargos públicos sociais. (São Paulo, 2016a).

No texto divulgado pela SMS-SP, reaparece um argumento recorrente entre especialistas médicos para a recomendação desse método: o fato de oferecer proteção contra a gravidez em longo prazo (três anos) e que "não exige disciplina da mulher, pois não é de uso diário". Embora destaquem que tais contraceptivos possam "ser interrompidos a qualquer momento, caso haja a vontade de engravidar, recuperando a fertilidade preexistente de forma rápida logo após a remoção", não se explicita que a remoção é médico-dependente, ou seja, a usuária precisará conseguir na rede de atenção quem o faça (São Paulo, 2016a). 
A portaria da Secretaria Municipal da Saúde $n^{\circ}$ 760, de 4 de maio de 2016, instituía as diretrizes para a prescrição e utilização do contraceptivo reversivo de ação prolongada, implante subdérmico de etonogestrel $(68 \mathrm{mg}$ ) na sua rede de serviços (São Paulo, 2016b). Amparada no artigo 226, $\$ 7^{\circ}$ da Constituição Federal e na Lei $n^{\circ}$ 9.263/1996 (Brasil, 1996), a portaria apontava as seguintes justificativas para tal iniciativa:

- adesão insatisfatória de usuárias de drogas a um método efetivo de contracepção;

- adesão limitada a métodos de uso mais frequentes de anticoncepção por moradoras de rua;

- os elevados índices de gravidez não planejada (52\%) entre mulheres que tiveram pelo menos um filho nos últimos 5 anos, verificados em pesquisa de 2015 com amostra de 1.047 mulheres, nas cinco Coordenadorias de Saúde da Secretaria Municipal da Saúde de São Paulo;

- a necessidade de estar disponível mais um método contraceptivo reversivo de ação prolongada além do dispositivo intrauterino (DIU) plástico modelo T $380 \mathrm{~mm} 2$ de cobre constante da REMUME-SP;

- a importância de adoção de práticas para o uso racional de fármacos que levem em conta a relação benefício-risco, isto é, o emprego de fármacos para a obtenção do melhor resultado com risco mínimo, para que se tenha a melhor efetividade.

A referida portaria sugeria a prescrição do implante "precedido da livre opção por parte da usuária ou representante legal mediante assinatura de termo de consentimento", para prevenção de gravidez nas "populações vulneráveis" (usuárias de drogas, mulheres em situação de rua), mencionando acompanhamento clínico periódico e remoção do dispositivo, em caso de efeitos adversos.

Essa portaria continha dois anexos, um Protocolo de Uso do Implante Subdérmico de Etonogestrel e o Termo de Consentimento Livre e Esclarecido (TCLE). Nesses documentos aparecem as mesmas justificativas do texto principal para indicação desse uso - "Em razão de existirem grupos de usuárias com elevado grau de vulnerabilidade social que dificulta o uso de métodos contraceptivos habituais" -, ressaltando-se as vantagens do implante (risco menor) em relação ao DIU de cobre, que pode vir a ser associado a infecções uterinas. Interessante notar que o protocolo assinala vários "eventos adversos" 
decorrentes do implante, classificando-os em "comuns"16 e "graves". Dentre os eventos graves, destacam-se: "Cardiovasculares: infarto do miocárdio; hematológicos: trombose venosa profunda, distúrbios tromboembólicos; neurológicos: acidente vascular cerebral trombótico; relativos à reprodução: gravidez ectópica rota; respiratórios: embolismo pulmonar." Por fim, o protocolo recomenda a ênfase ao uso de preservativo masculino, para prevenir infecções sexualmente transmitidas (IST) "frequentes nestas populações, constituindo também reforço à prevenção da gravidez pelo uso de contraceptivos reversíveis de ação prolongada, método de escolha para estas populações".

Além do protocolo acima referido, a portaria também apresentava o TCLE, citando os possíveis efeitos colaterais, tais como descritos no protocolo, e solicitava autorização para uso dos dados com devido anonimato (possivelmente para estudos clínicos realizados nos hospitais municipais, mas sem menção explícita a qualquer projeto de pesquisa). ${ }^{17}$ Outra dimensão a se notar é a não explicitação de quem seriam os "responsáveis legais" das adolescentes e mulheres "vulneráveis" em situação de rua para assinatura do documento, caso estas não se encontrassem em condições de fazê-lo. Como outros estudos mostram (Martin, 2006), o TCLE termina por assegurar proteção sobretudo aos médicos responsáveis pelo procedimento.

Pouco mais de um ano após a promulgação da Lei municipal $n^{\circ} 16.806$, de janeiro de 2018 (São Paulo, 2018a), o Decreto $n^{\circ}$ 58.693, de 2 de abril de 2019 (São Paulo, 2019b), vem regulamentá-la, e dispõe no artigo $1^{\circ}$ :

As mulheres da Cidade de São Paulo em situação de vulnerabilidade, atendidas na Rede Pública de Saúde, por meio de unidades diretas ou entidades conveniadas

16 Dentre os eventos comuns constam "dermatológicos: acne (6\% a 18,5\%); metabólicos endócrinos: aumento de peso ( $3 \%$ a $13,7 \%)$; gastrointestinais: dor abdominal (3\% a $15 \%)$, náusea ( $4 \%$ a 13,4\%); neurológicos: cefaleia ( $4 \%$ a $25 \%)$; psiquiátricos: mudança de humor (3\% a 14\%); relativos à reprodução: amenorreia (14\% a 33\%), dismenorreia (7,2\% a 10\%), menometrorragia (0,8\% a 16\%), menorragia ( $15 \%$ a $25 \%$ ), oligomenorreia (3,7\% a 33,6\%), vaginites ( $2 \%$ a $14,5 \%$ ); respiratórios: faringites (10,5\%), infecção do trato respiratório superior (12,6\%); reação no lugar do implante (2,5\% a 9,6\%); dor na mama (1,4\% a $12,8 \%)^{\prime \prime}$.

17 Não será possível aprofundar o debate sobre pesquisas realizadas em contextos institucionais, as relações sociais hierárquicas presentes, mediadas pelos profissionais de saúde imbuídos da autoridade científica e o grau de liberdade e agência que as mulheres podem ter para recusar a oferta de tal dispositivo no contexto em questão. 
a qualquer título, terão direito à inserção gratuita de implantes contraceptivos reversíveis de longa duração de etonogestrel, conforme protocolo da Secretaria Municipal da Saúde, respeitada a sua livre opção. (São Paulo, 2019b, grifo nosso).

Novamente, um perfil específico de "mulheres em situação de vulnerabilidade" é explicitado no artigo $2^{\circ}$ desse decreto, a saber, dependentes químicas; mulheres em situação de rua; e "adolescentes de regiões com vulnerabilidade social muito alta, conforme definido pelo Índice Paulista de Vulnerabilidade Social - IPVS 2010, elaborado pela Fundação SEADE" ${ }^{18}$ Por fim, o artigo $3^{\circ}$ dispõe que "as usuárias deverão ser informadas, pelos profissionais capacitados das Unidades de Saúde de Referência do Sistema Municipal de Saúde, sobre os benefícios, riscos, efeitos colaterais e duração deste método contraceptivo". Originalmente, o projeto de lei de 2015 (São Paulo, 2015) continha um parágrafo único com diversas categorias de mulheres consideradas "em situação de vulnerabilidade social" (profissionais do sexo, portadoras de HIV, adolescentes menores de 17 anos com gestações anteriores ou com "baixa adesão aos serviços de saúde", etc.), o qual foi vetado pelo prefeito ao sancionar a lei de 2018. Decerto, o decreto de 2019 vem corrigir tal abrangência e imprecisão que derivava da lei de 2018, o que poderia gerar juízos de valor ainda mais temerários.

Três anos após a portaria antes referida (São Paulo, 2016b) e a publicação da lei municipal (São Paulo, 2018a), um novo protocolo foi divulgado em 2019 e cita explicitamente: "Protocolo do Implante Subdérmico de Etonogestrel para Atendimento às Mulheres Vulneráveis" (São Paulo, 2019a). O documento está associado a um projeto intitulado "Atendimento às necessidades de planejamento familiar das usuárias de drogas, mulheres em situação de rua, adolescentes de muito alta vulnerabilidade social (Índice Paulista de Vulnerabilidade Social 2010 - Fundação SEADE) em idade reprodutiva na cidade de São Paulo". Todos esses documentos se amparam na Constituição Federal de 1988, onde se garante que "o planejamento familiar é livre decisão do casal, competindo ao Estado propiciar recursos educacionais e científicos para o exercício deste direito, sendo vedada qualquer forma coercitiva por parte de instituições oficiais ou privadas", e nos artigos da Lei do Planejamento Familiar de 1996 -

18 Fundação Sistema Estadual de Análise de Dados (Seade). 
"Art. $1^{\circ}$ : O planejamento familiar é direito de todo cidadão, observado o disposto nesta Lei; Art. $2^{\circ}$ : Para fins desta Lei, entende-se planejamento familiar como o conjunto de ações de regulação da fecundidade que garanta direitos iguais de constituição, limitação ou aumento da prole pela mulher, pelo homem ou pelo casal" (Brasil, 1996).

Essas iniciativas invocam o ideário dos direitos humanos, numa clara estratégia de busca de legitimidade, na medida em que reforçam princípios constitucionais caros à democracia brasileira. Nesse segundo protocolo (São Paulo, 2019a), destaca-se que o implante tem "uma eficácia superior a 99\%, igual ou superior à eficácia da laqueadura tubária”. E são mencionadas outras vantagens como: praticidade e longa duração; não interferência na relação sexual; na amamentação; melhoria de cólicas menstruais; preservação de massa óssea. Atenua-se, todavia, algumas de suas desvantagens como a alta frequência de possíveis pacientes que possam ter sangramentos irregulares. Importante mencionar que as destinatárias do projeto são mulheres "vulneráveis", que não possuem condições adequadas de habitação, espaço para cuidados íntimos e banho, nem sequer absorventes para enfrentar tais problemas de saúde. Estes são claramente minimizados em prol de um bem maior: a não reprodução por três anos. O trecho a seguir é elucidativo:

Irregularidades da menstruação. Na maioria dos casos, há sangramento irregular, podendo haver aumento do fluxo menstrual ou ausência de menstruação. Estas alterações são mais comuns no primeiro ano e não têm consequências negativas na saúde da mulher. De cada 100 mulheres, 15 terão sangramento mais frequente. (São Paulo, 2019a, grifo nosso).

Ainda no rol das desvantagens, são listadas "algumas alterações da pele, dores de cabeça, enjoos, aumento da sensibilidade mamária e variações do humor (semelhantes às que ocorrem com outros métodos contraceptivos como a pílula)"; cistos benignos nos ovários, que não demandam tratamento.

Comparando os documentos - protocolo e TCLE - das versões de 2016 e de 2019, percebe-se que a redação mais detalhada dos efeitos colaterais presente no primeiro protocolo desaparece e ganha contornos mais genéricos, de caráter habitual neste último documento. Embora também esteja previsto acompanhamento clínico das usuárias, o grau de desarticulação e de desmonte dos serviços 
e das políticas de saúde que tem se processado recentemente nos deixa apreensivas quando à seriedade e garantias desse seguimento ao longo dos anos, sobretudo no que concerne à mobilidade das mulheres que vivem em situação de rua. ${ }^{19}$ Por fim, o protocolo elege como prioridade para a oferta do implante as "usuárias de drogas em idade reprodutiva; mulheres em idade reprodutiva em situação de rua; adolescentes de prefeituras regionais com alta taxa de fecundidade".

O documento mais recente de regulamentação e institucionalização de LARC na rede pública municipal de saúde data de agosto de 2020 e versa sobre o "DIU hormonal". A Nota técnica n 007/2020 estabelece "os critérios para indicação do Sistema Intrauterino (SIU) de levonogestrel nas unidades de saúde da Secretaria Municipal da Saúde de São Paulo" (São Paulo, 2020). Novamente, as considerações que abrem o documento são plausíveis, não fosse o fato de se restringirem às mulheres "vulneráveis". Assim, apontam em um misto de critérios e justificativas:

A importância da ampliação das opções contraceptivas para redução da gravidez não planejada em mulheres vulneráveis;

A efetividade e menor taxa de falha dos contraceptivos reversíveis de longa ação; A necessidade da melhoria dos indicadores de saúde materno-infantil e qualidade de vida da mulher no município de São Paulo. (São Paulo, 2020, grifo nosso).

O acesso ao SIU-LNG é facultado às mulheres com pelo menos uma das seguintes condições: "Síndrome anêmica; anemia falciforme; após cirurgia bariátrica; HIV positiva fase 1 e 2; adolescentes de regiões de alta vulnerabilidade social; cardiopatias de alto risco e com contraindicação à gravidez; cardiopatias de risco intermediário à gestação; sangramento uterino anormal." No protocolo para utilização e dispensação do endoceptivo (DIU Mirena ${ }^{\circledR}$ ), publicado em 2018, pela SMS-SP (São Paulo, 2018b), destacava-se sobretudo suas finalidades

19 Resultado do desfinanciamento do SUS, em acordo a uma política de desmonte do Estado pelo atual governo brasileiro, há cada vez menos equipamentos, profissionais e ações de saúde disponíveis à população, bem como menos resolutividade na assistência em função da crescente precariedade e desarticulação no que concerne ao princípio da atenção hierarquizada. Essa é apenas uma face de um cenário desfavorável para a integralidade das ações em saúde, que contribui para desestruturação da diretriz de territorialização das ações em saúde, por conseguinte, da captação e acompanhamento de potenciais usuárias em situação de rua. 
terapêuticas específicas e menos sua dimensão contraceptiva, que aparece agora potencializada na nota técnica de 2020, nos sugerindo uma expansão de seus usos para um público mais amplo do que as indicações terapêuticas antes previstas.

\section{Mulheres "vulneráveis" e a produção de uma cidadania de segunda classe}

A análise do material empírico apresentado evidencia a recorrente categoria de mulheres "vulneráveis". Sob essa insígnia, estão compreendidas mulheres jovens, com pertencimento social e racial precisos, que vivem em territórios também racializados (ruas, "cracolândia”, ${ }^{20}$ favelas, bairros periféricos), classificadas como usuárias de drogas, adolescentes de regiões “altamente vulneráveis" segundo indicadores estaduais, ${ }^{21}$ portadoras de HIV, enfim, cidadãs de segunda classe, retratadas pelo poder público como necessitando de intervenção estatal para controle da capacidade reprodutiva de seus corpos. Corpos sexuais desviantes, dissidentes que insistem em permanecer vivos e se reproduzir.

O exame da oferta "seletiva" de LARC no sistema público de saúde do município de São Paulo assinala, igualmente, ideias predominantes no senso comum e na área da saúde relativas à incapacidade feminina de autodeterminação reprodutiva, às descontinuidades contraceptivas que resultam em gestações imprevistas/não planejadas, tomadas invariavelmente como fracassos das mulheres, à compreensão de determinadas maternidades não socialmente aceitas, sendo consideradas "maternidades de risco", como demonstra Faya-Robles (2015) em sua etnografia com mulheres jovens de camadas populares, usuárias de serviços públicos de saúde de Recife e do Rio de Janeiro. A tônica subjacente a tais acusações frequentemente sublinha uma racionalidade

20 Região situada no centro da cidade de São Paulo, ocupada por pessoas em situação de rua, dependentes químicos e frequentada por traficantes de crack, que comercializam seus produtos entre usuários.

21 O Índice Paulista de Vulnerabilidade Social 2010, elaborado pelo governo do estado de São Paulo "consiste em uma tipologia de situações de exposição à vulnerabilidade, agregando aos indicadores de renda outros referentes ao ciclo de vida familiar e escolaridade, no espaço intraurbano" (Fundação Seade, 2010, p. 9), estando baseado em dados do Censo IBGE 2010. 
individual e uma responsabilização e culpabilização femininas, como vimos na noção de healthism, deixando de escanteio o enfrentamento de dimensões estruturais de classe social, gênero, raça, geração (para referir alguns marcadores sociais de diferença) que incidem sobre o campo da reprodução.

Recobertas pelo adjetivo "vulneráveis", nota-se um deslizamento semântico derivado dessa classificação inicial, elaborada por agências públicas para orientação de programas sociais, para uma classificação social de sujeitos (mulheres) inferiores, de segunda classe, para em seguida também se tornar uma categoria de acusação moral. De um atributo que se referia a uma condição social de existência, não fixa ou permanente, passível de transformação social, passamos a um atributo essencial, substantivo, corporificado, identitário, que designa quem são tais mulheres, fixando tais estereótipos como destinos naturais de vida. Em outras palavras, a categoria "vulnerabilidade", inicialmente utilizada para se referir a gradientes de desigualdade social que demandariam instrumentos de proteção social para compensar disparidades socioestruturais, termina sendo biologizada. Ao invés de tomá-la como uma condição social circunstancial, ela aparece entranhada nos corpos femininos, essencializada para justificar tais intervenções públicas. Não se inquire sobre tal condição social, tampouco em como ela fere a dignidade e integridade dessas existências. A produção dessa subalternidade vem acompanhada da necessidade de regular, de forma "eficaz", ou seja, alheia a sua vontade, a possibilidade de sua reprodução. Envoltos em uma retórica de direitos reprodutivos, mediada por indicadores de saúde, metas, custos financeiros, como destaca Senderowicz (2019), tais iniciativas produzem uma naturalização ou institucionalização de uma subcidadania, de uma condição inferior de mulheres, inaptas ao cuidado de si, cujos corpos são abjetos (Rui, 2014) e sua existência desprezível, descartável para o restante da sociedade.

A categoria de "precariedade", formulada por Judith Butler (2011), nos parece profícua para designar tais vidas femininas, que somente importam pelo risco de se reproduzir e de produzirem degeneração (Rapp, 2019; Valdez; Deomampo, 2019; Werneck, 2004). Não há reconhecimento social de sua alteridade; ao contrário, são vidas que não importam ou são destituídas de valor para serem respeitadas e cuidadas. Mulheres "vulneráveis", com "vidas precárias", cuja potencialidade reprodutiva necessita de governo, materializado em seus corpos, através de modernos dispositivos de controle (da fecundidade) de longa 
duração. Tais corpos serão penetrados pelo Estado, via inserção dessas biotecnologias, consideradas ferramentas de inclusão social.

Essa tônica colide frontalmente com a defesa de uma perspectiva que advoga a indissociabilidade entre direitos reprodutivos e direitos sociais e econômicos. Esse é o ponto nodal da concepção de justiça reprodutiva, aportado através do protagonismo das feministas negras, desde o final da década de 1990, que ressalta a imbricada interseção entre dimensões estruturantes das interações sociais e da vida em sociedade como classe social, raça, gênero, nacionalidade, sexualidade e reprodução.

Não é aleatório que a organização feminista SisterSong Women of Color Reproductive Justice Collective (2016), berço do debate sobre justiça reprodutiva nos EUA, tenha lançado um manifesto intitulado LARC - Statement of Principles, em conjunto com National Women's Health Network, assinado por múltiplas instituições de defesa dos direitos das mulheres, reassegurando a liberdade das mulheres no tocante às suas decisões reprodutivas e as necessárias condições para que a escolha de um método contraceptivo seja feito "de maneira medicamente ética e culturalmente competente".

We reject efforts to direct women toward any particular method and caution providers and public health officials against making assumptions based on race, ethnicity, age, ability, economic status, sexual orientation, or gender identity and expression. [...] Women should have the right and the ability to control their own fertility whether planning, preventing or terminating a pregnancy. Marginalized communities, and particularly women of color, have experienced many forms of reproductive oppression, from forced sterilization to restrictions on abortion access to coercive limits on their ability to have children, and they continue to face high rates of maternal mortality. We believe articulating these principles is necessary to protect the bodily autonomy and to respect the agency, health and dignity of marginalized women so that those who have historically been oppressed or harmed feel safe when making reproductive decisions. This is a critical step forward. This is what reproductive justice looks like. (SisterSong Women of Color Reproductive Justice Collective, 2016).

Por fim, mas não menos importante, a recorrente menção a mulheres "vulneráveis" nos documentos oficiais, como objeto prioritário de determinadas "ações 
de saúde", explicita a permanência de concepções eugênicas e racistas, que marcaram boa parte do debate sobre população e desenvolvimento nos séculos XIX e XX. O recurso à linguagem dos direitos e a mobilização de argumentos do campo da proteção à saúde imprimem uma sofisticação à retórica que busca tornar irrefutável a oferta dessa tecnologia LARC a mulheres socialmente excluídas, cujos corpos não podem gozar de liberdade/autonomia reprodutiva e precisam ser tutelados.

Impossível não identificar nos procedimentos vistos nas portarias, protocolos, entre outros, mecanismos de coerção assinalados por Senderowicz (2019) em sua pesquisa. Não encontramos a mesma ênfase dada aos métodos LARC para esse grupo de mulheres em relação a outros métodos contraceptivos, nem ao conjunto mais amplo de cuidados em saúde reprodutiva dessas mulheres (exames ginecológicos, preventivos para câncer, para diagnóstico de IST, etc.). Trata-se de uma ação dirigida e impositiva que certamente não deixará margem de escolha às mulheres abordadas.

\section{Na contramão da universalização da oferta contraceptiva no SUS}

Universalidade e integralidade são dimensões basilares das políticas públicas de saúde construídas nas últimas quatro décadas no Brasil. O conceito de integralidade diz respeito tanto ao aspecto organizacional do sistema de saúde quanto às próprias práticas de atenção que articulam ações de prevenção, promoção, recuperação e reabilitação de saúde, assim como uma perspectiva não reducionista de processos de saúde e doença. Ele remete, portanto, a uma compreensão ampliada de saúde, necessariamente transversalizada por outras dimensões estruturais como acesso à educação, moradia, trabalho, renda, segurança, alimentação. O Programa de Assistência Integral à Saúde da Mulher (PAISM), lançado em 1983 pelo Ministério da Saúde, incorporou essa concepção, promovendo um claro rompimento com ações governamentais até então de cunho materno-infantilista (Diniz, 2012). Em sua origem, o PAISM propunha uma nova mirada para a saúde da mulher, não mais restrita ao ciclo gravídico-puerperal, mas incorporando dimensões relativas a outros momentos do curso de vida das mulheres. É preciso mencionar a interseção desses conceitos (ou 
ideários políticos) com a noção de direitos reprodutivos que também vinham se constituindo no cenário local e global. A defesa de uma assistência à saúde que atendesse às demandas das mulheres em sua integralidade passava por ter acesso a formas de controle da própria capacidade reprodutiva. A busca pelo acesso universal e gratuito ao conjunto mais amplo possível de métodos contraceptivos através do SUS é um importante capítulo dessa história de construção de uma política integral de saúde da mulher (Brasil, 2004).

No entanto, temos assistido, sobretudo na última década, a importante revés no campo das políticas públicas de saúde, que vêm sendo paulatinamente erodidas, não apenas em função de subfinanciamento imposto com a Emenda Constitucional 95, que limita por 20 anos o teto de gastos públicos, inclusive com saúde. Também as ações que concernem à saúde da mulher têm sofrido recrudescimento importante no plano normativo: cita-se, por exemplo, o brutal retorno às ações focadas ao período gravídico-puerperal através da estratégia conhecida por Rede Cegonha (Brasil, 2013), lançada em 2011, cujos componentes principais estão voltados para garantia do acesso e cuidado no período pré-natal, parto e nascimento, puerpério e saúde da criança. Nesse sentido, a oferta seletiva de determinados métodos contraceptivos a segmentos populacionais específicos pode também ser compreendida como mais um elemento a reforçar essa tendência mais ampla de destituição de princípios democráticos e equitativos com os quais as políticas sanitárias foram construídas no período de redemocratização do país.

Acreditamos que a atenção dos movimentos feministas e negros no Brasil, do ativismo social em defesa do SUS, tão ameaçado em tempos de desmonte das políticas públicas, esteja compreensivelmente mais voltada para os temas relativos à saúde reprodutiva que provocam diretamente mortes de mulheres, tais como o aborto inseguro e a mortalidade materna, a qual reflete desassistência no período do pré-natal, parto e pós-parto. Todavia, indagamos se a questão da contracepção reversível de longo prazo, que se instala no SUS não de modo universal para todas as mulheres que a desejarem, mas de modo restrito, seletivo a um conjunto específico de mulheres, tomadas como "vulneráveis", esteja passando despercebida em sua gravidade.

Como o acesso a métodos contraceptivos se constitui um direito das mulheres, toda a complexidade que subjaz a essa oferta e o modo (violento) como ela é apresentada pode estar sendo subvalorizado pelas instâncias de 
controle social do SUS e por movimentos sociais organizados. ${ }^{22}$ As significativas dificuldades para acesso às laqueaduras tubárias no SUS, permeadas pelo racismo institucional e por interesses médicos corporativos, fartamente documentadas em estudos etnográficos realizados no país (Carvalho, 2017; Corossacz, 2009; Dalsgaard, 2006; Edu, 2018, 2019; Faya-Robles, 2015), podem estar funcionando como um caminho que vem sendo pavimentado para a entrada maciça, em larga escala, dos métodos LARC no Brasil, atendendo, assim, a interesses empresariais, de corporações médicas, de gestores públicos e, não menos importante, de produção de conhecimentos científicos, por meio de potenciais participantes de estudos clínicos oriundas do SUS.

As justificativas técnicas e políticas para se fomentar a inserção de métodos LARC em detrimento das laqueaduras tubárias reiteram, em primeiro lugar, o caráter controverso do tema da esterilização feminina no país, com histórico de procedimentos cirúrgicos em massa, à revelia das mulheres, nas décadas de 1970 e 1980, cuja reação da sociedade civil organizada naquela ocasião conseguiu denunciar e coibir a continuidade de tais abusos, gerando então um certo receio da classe médica sobre processos/punições em torno do procedimento.

Em segundo lugar, advoga-se que os procedimentos para inserção dos métodos LARC são ambulatoriais, de baixo risco, relativamente rápidos, exigindo o trabalho de poucos profissionais de saúde treinados para atender um número ampliado de mulheres, sem demandas por internações hospitalares ou ocupação de centros cirúrgicos, tal como previsto na legislação para a laqueadura. $\mathrm{Na}$ racionalidade tecnocrática de gestores públicos, isso significa uma economia vultosa de recursos em saúde, apesar de o preço dos dispositivos não ser desprezível.

A euforia com os métodos LARC está indubitavelmente relacionada ao seu caráter de reversibilidade, em comparação à laqueadura, e ainda a pouca (inexistente) celeuma política em seu entorno, que faz com que alguns autores os estejam qualificando como "soft sterilization" (Brian; Grzanka; Mann, 2020, p. 5, grifo dos autores): "A version of eugenics whereby the state does not have to blatantly infringe upon civil rights in order to achieve its aims. Instead,

22 Uma exceção nesse cenário foi a rápida mobilização social ocorrida em 2018, em Porto Alegre, em torno de iniciativa pública para inserção de dispositivos intrauterinos (SIU-LNG) em adolescentes em acolhimento institucional, revertida posteriormente. Para mais detalhes, cf. Brandão e Cabral (2021). 
soft sterilisation is involuntarily, 'temporarily' chosen - eugenics vis-à-vis empowerment."

Com nível de eficácia prática semelhante àquele obtido com a esterilização irreversível, os LARC vão ganhando destaque dentre as opções contraceptivas disponíveis no mercado. As reticências apontadas se colocam em relação aos usos (e abusos) que se faz com essa tecnologia biopolítica. Ademais, as múltiplas racionalidades subjacentes à oferta seletiva de LARC coloca em relevo não apenas seu (des)encontro com princípios ético-políticos comprometidos com valores democráticos e de justiça social, como também evidencia as infindáveis disputas morais no campo da reprodução, em que as mulheres, em especial, são sempre tomadas como objetos da intervenção médica e estatal. Nesse caso, a cidadania mediada pelo útero evidencia o valor social dessas mulheres, reduzidas em sua existência ao perigo da reprodução. Os métodos modernos LARC seriam assim os artefatos de inclusão social de mulheres absolutamente excluídas pela sociedade brasileira.

\section{Referências}

AGORA é lei: contraceptivo de longa duração será disponibilizado na rede pública. São Paulo: Câmara Municipal de São Paulo, 23 jan. 2018. Disponível em: http://www. saopaulo.sp.leg.br/blog/agora-e-lei-contraceptivo-de-longa-duracao-sera-disponibilizado-na-rede-publica/. Acesso em: 3 mar. 2020.

AMERICAN ASSOCIATION OF PEDIATRICS. Policy statement: contraception for adolescents. Pediatrics, [s. l.], v. 134, n. 4, p. e1244-e1256, 2014.

BENDIX, D. et al. Targets and technologies: Sayana Press and Jadelle in contemporary population policies. Gender, Place \& Culture, [s. l.], v. 27, n. 3, p. 351-369, 2020.

BERQUÓ, E. Brasil, um caso exemplar - a anticoncepção e partos cirúrgicos à espera de uma ação exemplar. Revista Estudos Feministas, Florianópolis, v. 1, n. 2, p. 367-381, 1993.

BERQUÓ, E.; CAVENAGHI, S. Direitos reprodutivos de mulheres e homens face à nova legislação brasileira sobre esterilização voluntária. Cadernos de Saúde Pública, Rio de Janeiro, v. 19, n. 2, p. 441-453, 2003.

BHATIA, R. et al. A feminist exploration of "populationism": engaging contemporary forms of population control. Gender, Place \& Culture, [s. l.], v. 27, n. 3, p. 333-350, 2020. 
BORGES, A. L. V. et al. Descontinuidades contraceptivas no uso do contraceptivo hormonal oral, injetável e do preservativo masculino. Cadernos de Saúde Pública, Rio de Janeiro, v. 37, n. 2, e00014220, 2021.

BRANDÃO, E. R. Métodos contraceptivos reversíveis de longa duração no Sistema Único de Saúde: o debate sobre a (in)disciplina da mulher. Ciência \& Saúde Coletiva, Rio de Janeiro, v. 24, n. 3, p. 875-879, 2019.

BRANDÃO, E. R.; CABRAL, C. S. Juventude, gênero e justiça reprodutiva: iniquidades em saúde no planejamento reprodutivo no Sistema Único de Saúde. Ciência \& Saúde Coletiva, Rio de Janeiro, v. 26, n. 7, p. 2673-2682, 2021.

BRANDÃO, E. R.; PIMENTEL, A. C. L. Essure no Brasil: desvendando sentidos e usos sociais de um dispositivo biomédico que prometia esterilizar mulheres. Saúde e Sociedade, São Paulo, v. 29, n. 1, e200016, 2020.

BRASIL. Lei $n^{\circ}$ 9.263, de 12 de janeiro de 1996. Regula o $§ 7^{\circ}$ do art. 226 da Constituição Federal, que trata do planejamento familiar, estabelece penalidades e dá outras providências. Brasília: Presidência da República, 1996. Disponível em: http://www. planalto.gov.br/ccivil_03/leis/19263.htm. Acesso em: 10 out. 2020.

BRASIL. Ministério da Saúde. Política Nacional de Atenção Integral a Saúde da Mulher: princípios e diretrizes. Brasília: MS, 2004.

BRASIL. Ministério da Saúde. Pesquisa Nacional de Demografia e Saúde da Criança e da Mulher: PNDS 2006: relatório final. Brasília: MS, 2008.

BRASIL. Ministério da Saúde. Conheça a Rede Cegonha. Brasília: MS, 2013. Disponível em: https://bvsms.saude.gov.br/bvs/folder/rede_cegonha.pdf. Acesso em: 15 out. 2020.

BRASIL. Ministério da Saúde. Portaria n 3.265 de 1 de dezembro de 2017. Altera o Anexo XXVIII da Portaria de Consolidação n ${ }^{\circ}$ 2/GM/MS, de 28 de setembro de 2017, que dispõe sobre a ampliação do acesso ao Dispositivo Intrauterino Tcu 380 (DIU de cobre) no âmbito do Sistema Único de Saúde (SUS). Diário Oficial da União: seção 1, Brasília, n. 234, p. 867, 7 dez. 2017.

BRASIL. Ministério da Saúde. Secretaria de Ciência, Tecnologia, Inovação e Insumos Estratégicos em Saúde. Portaria $\mathrm{n}^{\circ}$ 13, de 19 de abril de 2021. Torna pública a decisão de incorporar o implante subdérmico de etonogestrel, condicionada à criação de programa específico, na prevenção da gravidez não planejada para mulheres em idade fértil: em situação de rua; com HIV/AIDS em uso de dolutegravir; em uso de talidomida; privadas de liberdade; trabalhadoras do sexo; e em tratamento de tuberculose em uso de aminoglicosídeos, no âmbito do Sistema Único de Saúde - SUS. Diário Oficial da União: seção 1, Brasília, n. 74, p. 235, 22 abr. 2021. 
BRIAN, J. D.; GRZANKA, P. R.; MANN, E. S. The age of LARC: making sexual citizens on the frontiers of technoscientific healthism. Health Sociology Review, [s. l.], v. 29, n. 3, p. 312-328, 2020.

BUTLER, J. Vida precária. Contemporânea, São Carlos, n. 1, p. 13-33, 2011.

CABRAL, C. S. Contraception et stérilisation des jeunes femmes au Brésil. Autrepart, [s. l.], v. 70, n. 2, p. 165-183, 2014.

CARNEIRO, A. S. A construção do outro como não-ser como fundamento do ser. 2005. Tese (Doutorado em Educação) - Faculdade de Educação, Universidade de São Paulo, São Paulo, 2005.

CARRARA, S. Moralidades, racionalidades e políticas sexuais no Brasil contemporâneo. Mana, Rio de Janeiro, v. 21, n. 2, p. 323-345, ago. 2015.

CARRARA, S.; VIANNA, A. Os direitos sexuais e reprodutivos no Brasil a partir da “Constituição Cidadã”. In: OLIVEN, R. G.; RIDENTI, M.; BRANDÃO, G. M. (org.). A Constituição de 1988 na vida brasileira. São Paulo: Hucitec, 2008. p. 334-359.

CARVALHO, L. D. P. Da esterilização ao Zika: interseccionalidade e transnacionalismo nas políticas de saúde para as mulheres. 2017. Tese (Doutorado em Ciência Política) - Faculdade de Filosofia, Letras e Ciências Humanas, Universidade de São Paulo, São Paulo, 2017.

CAVENAGHI, S.; ALVES, J. E. D. The everlasting outmoded contraceptive method mix in Brazil and its legacy. Revista Brasileira de Estudos da População, São Paulo, v. 36, e0103, 2019.

CE É O $1^{\circ}$ DO BRASIL a usar implante contraceptivo. Diário do Nordeste, [s. l.], 22 set. 2010. Disponível em: https://diariodonordeste.verdesmares.com.br/metro/ce-e-o-1-do-brasil-a-usar-implante-contraceptivo-1.536907. Acesso em: 28 abr. 2020.

CLARKE, A. et al. Biomedicalization: technoscientific transformations of health, illness and US biomedicine. American Sociological Review, [s. l.], v. 68, n. 2, p. 161-194, Apr. 2003.

CLARKE, A. et al. Biomedicalization: technoscience, health, and illness in the U.S. Durham: Duke University Press, 2010.

CLARKE, A.; SHIM, J. Medicalization and biomedicalization revisited: technoscience and transformations of health, illness and american medicine. In: PESCOSOLIDO, B. A. et al. (ed.). Handbook of the sociology of health, illness, and healing. New York: Springer, 2011. p. 173-199.

COLLIN, J. On social plasticity: the transformative power of pharmaceuticals on health, nature and identity. Sociology of Health \& Illness, [s. l.], v. 38, n. 1, p. 73-89, 2016. 
COROSSACZ, V. R. O corpo da nação: classificação racial e gestão social da reprodução em hospitais da rede pública do Rio de Janeiro. Rio de Janeiro: Editora da UFRJ, 2009.

CORRÊA, S.; PETCHESKY, R. Direitos sexuais e reprodutivos: uma perspectiva feminista. Physis: revista de saúde coletiva. Rio de Janeiro, v. 6, n. 1-2, p. 147-177, 1996.

CRAWFORD, R. Healthism and the medicalization of everyday life. International Journal of Health Services, [s. l.], v. 10, n. 3, p. 365-388, 1980.

DALSGAARD, A. L. Vida e esperanças: esterilização feminina no Nordeste. São Paulo: Editora da Unesp, 2006.

DINIZ, S. Materno-infantilism, feminism and maternal health policy in Brazil. Reproductive Health Matters, [s. l.], v. 20, n. 39, p. 125-132, 2012.

EDU, U. F. When doctors don't tie: hierarchical medicalization, reproduction and sterilization in Brazil. Medical Anthropology Quarterly, [s. l.], v. 32, n. 4, p. 556-573, 2018.

EDU, U. F. Aesthetics politics: negotiations of black reproduction in Brazil. Medical Anthropology, [s. l.], v. 38, n. 8, p. 680-694, 2019.

EPSTEIN, S.; MAMO, L. The proliferation of sexual health: diverse social problems and the legitimation of sexuality. Social Science \& Medicine, [s. l.], v. 188, p. 176-190, 2017.

FAYA-ROBLES, A. Da gravidez de "risco" às "maternidades de risco": biopolítica e regulações sanitárias nas experiências de mulheres de camadas populares de Recife. Physis: revista de saúde coletiva. Rio de Janeiro, v. 25, n. 1, p. 139-169, 2015.

FEDERAÇÃO BRASILEIRA DAS ASSOCIAÇÕES DE GINECOLOGIA E OBSTETRÍCIA. Contracepção reversível de longa ação. São Paulo: Febrasgo, nov. 2016. (Série orientações e recomendações Febrasgo, v. 3, n. 1).

FERNANDES, C. "Elas fazem filhos demais": a ideologia da gravidez planejada frente à violência de Estado nos territórios populares. 2019a. Trabalho apresentado no $43^{\circ}$ Encontro Anual da ANPOCS, Caxambu, 2019.

FERNANDES, C. Figuras do constrangimento: as instituições de Estado e as políticas de acusação sexual. Mana, Rio de Janeiro, v. 25, n. 2, p. 365-390, 2019b.

FERREIRA, L.; LOWENKRON, L. (org.). Etnografia de documentos: pesquisas antropológicas entre papéis, carimbos e burocracias. Rio de Janeiro: E-papers, 2020.

FONSECA, C. et al. Apresentação. Horizontes Antropológicos, Porto Alegre, ano 22, n. 46, p. 9-34, jul./dez. 2016. 
FOUCAULT, M. História da sexualidade I: a vontade de saber. 13. ed. Rio de Janeiro: Graal, 1999.

FUNDAÇÂO SEADE. Índice Paulista de Vulnerabilidade Social - versão 2010. São Paulo: Governo do Estado de São Paulo, 2013.

GOMEZ, A. M.; FUENTES, L.; ALLINA, A. Women or LARC first? Reproductive autonomy and the promotion of Long-Acting Reversible Contraceptive methods. Perspectives on Sexual and Reproductive Health, [s. l.], v. 46, n. 3, p. 171-175, 2014.

GUBRIUM, A. C. et al. Realizing reproductive realth equity needs more than Long-Acting Reversible Contraception (LARC). American Journal of Public Health, [s. l.], v. 106, n. 1, p. 18-19, 2016.

HENDRIXSON, A. Population control in the troubled present: the " 120 by 20 " target and implant access program. Development and Change, [s. l.], v. 50, n. 3, p. 786-804, 2019.

HENDRIXSON, A. et al. Confronting populationism: feminist challenges to population control in an era of climate change. Gender, Place \& Culture, [s. l.], v. 27, n. 3, p. 307$315,2020$.

HIGGINS, J. A. Celebration meets caution: LARC's boons, potential busts, and the benefits of a reproductive justice approach. Contraception, [s. l.], v. 89, n. 4, p. 237-241, 2014.

LOWENKRON, L.; FERREIRA, L. Anthropological perspectives on documents. Ethnographic dialogues on the trail of police papers. Vibrant: virtual Brazilian Anthropology, Brasília, v. 11, n. 2, p. 76-112, July/Dec. 2014.

MARTIN, E. A mulher no corpo: uma análise cultural da reprodução. Rio de Janeiro: Garamond, 2006.

MORGAN, L. M. Reproductive governance, redux. Medical Anthropology, [s. l.], v. 38, n. 2, p. 113-117, 2019.

MORGAN, L. M.; ROBERTS, E. F. Reproductive governance in Latin America. Anthropology \& Medicine, [s. l.], v. 19, n. 2, p. 241-253, Aug. 2012.

NASCIMENTO, N. N. C. Contraceptivos hormonais reversíveis de longo prazo: análise socioantropológica das controvérsias que cercam sua circulação no âmbito do Sistema Único de Saúde no Brasil. 2020. Dissertação (Mestrado em Saúde Coletiva) - Instituto de Estudos em Saúde Coletiva, Universidade Federal do Rio de Janeiro, Rio de Janeiro, 2020.

PENNA, I. A. A.; BRITO, M. B. A importância da contracepção de longo prazo reversível. Femina, São Paulo, v. 43, supl. 1, p. 1-6, 2015. 
PONCE DE LEON, R. G. et al. Contraceptive use in Latin America and the Caribbean with a focus on long-acting reversible contraceptives: prevalence and inequalities in 23 countries. Lancet Global Health, [s. l.], v. 7, n. 2, p. e227-e235, 2019.

PRICE, K. What is reproductive justice? How women of color activists are redefining the pro-choice paradigm. Meridians: feminism, race, transnationalism, [s. l.], v. 10, n. 2, p. 42-65, 2010.

RAPP, R. Race \& reproduction: an enduring conversation. Medical Anthropology, [s. l.], v. 38, n. 8, p. 725-732, 2019.

ROBERTS, D. Reproductive justice, not just rights. Dissent, [s. l.], v. 62, n. 4, p. 79-82, 2015.

ROSS, L. J. Reproductive justice as intersectional feminist activism. Souls, [s. l.], v. 19, n. 3, p. 286-314, 2017.

RUI, T. Nas tramas do crack: etnografia da abjeção. São Paulo: Terceiro Nome, 2014.

SÃO PAULO (Município). Projeto de Lei nº 0467/2015 da Vereadora Patrícia Bezerra $(P S D B)$. Dispõe sobre política de proteção às mulheres em situação de vulnerabilidade, pela rede pública de saúde com a utilização do contraceptivo reversível de longa duração de etonogestrel, e dá outras providências. São Paulo: Câmara Municipal de São Paulo, 9 set. 2015. Disponível em: http://documentacao.saopaulo.sp.leg.br/ iah/fulltext/projeto/PL0467-2015.pdf. Acesso em: 3 mar. 2020.

SÃO PAULO. Secretaria Municipal da Saúde. Rede Municipal adquire implantes contraceptivos de longa duração para ampliar gama do planejamento reprodutivo. São Paulo: SMS, 11 fev. 2016a. Disponível em: http://www.prefeitura.sp.gov.br/cidade/secretarias/saude/noticias/?p=211815. Acesso em: 10 mar. 2020.

SÃO PAULO. Secretaria Municipal da Saúde. Portaria SMS nº 760 de 4 de maio de 2016. Institui as diretrizes para a prescrição e utilização do contraceptivo reversivo de ação prolongada, implante subdérmico de etonogestrel $68 \mathrm{mg}$, na rede de serviços da Secretaria Municipal da Saúde. São Paulo: SMS, 4 maio 2016b. Disponível em: http://legislacao.prefeitura.sp.gov.br/leis/portaria-secretaria-municipal-da-saude-sms-760-de-4-de-maio-de-2016. Acesso em: 6 abr. 2020.

SÃO PAULO (Município). Lei n ${ }^{\circ} 16.806$ de 19 de janeiro de 2018. Dispõe sobre política de proteção às mulheres em situação de vulnerabilidade pela Rede Pública de Saúde, com a utilização do Contraceptivo Reversível de Longa Duração de Etonogestrel, e dá outras providências. Diário Oficial [da] Cidade de São Paulo, São Paulo, ano 63, n. 14, 20 jan. 2018a. Disponível em: http://www.saopaulo.sp.leg.br/wp-content/uploads/2018/01/lei-contraceptivo.pdf. Acesso em: 10 mar. 2020. 
SÃO PAULO. Secretaria Municipal da Saúde. Coordenação de Atenção Básica. Protocolo para utilização e dispensação do endoceptivo (MIRENA). São Paulo: SMS, ago. 2018b. Disponível em: https://www.prefeitura.sp.gov.br/cidade/secretarias/upload/Protocolo\%20SIUlevonorgestrel\%20para\%20Sangramento\%20Uterino\%20Anormal\%20 21818(1).pdf. Acesso em: 4 set. 2020.

SÃO PAULO. Secretaria Municipal da Saúde. Coordenação da Atenção Básica. Protocolo do implante subdermico de etonogestrel para atendimento às mulheres vulneráveis. São Paulo: SMS, mar. 2019a. Disponível em: https://www.prefeitura.sp.gov.br/ cidade/secretarias/upload/PROTOCOLO\%2OIMPLANTE\%20SD\%20ETONOGESTREL\%2OMULHERES\%20VULNERAVEIS\%20SMSSP\%2032019.pdf. Acesso em: 4 set. 2020.

SÃO PAULO (Município). Decreto $n^{0} 58.693$, de 2 de abril de 2019. Regulamenta a Lei $\mathrm{n}^{\circ} 16.806$, de 19 de janeiro de 2018, que dispõe sobre política de proteção às mulheres em situação de vulnerabilidade pela Rede Pública de Saúde, com a utilização do Contraceptivo Reversível de Longa Duração de Etonogestrel. São Paulo: Prefeitura de São Paulo, 2 abr 2019b. Disponível em: http://legislacao.prefeitura.sp.gov.br/leis/ decreto-58693-de-2-de-abril-de-2019. Acesso em: 10 mar. 2020.

SÃO PAULO. Secretaria Municipal da Saúde. Coordenação da Atenção à Saúde. Departamento de Atenção Básica. Nota técnica $n^{0}$ 007/2020. Estabelece os critérios para indicação do Sistema Intrauterino (SIU) de levonogestrel nas unidades de saúde da Secretaria Municipal de Saúde de São Paulo. São Paulo: SMS, 13 ago. 2020. Acesso em: 4 set. 2020.

SENDEROWICZ, L. "I was obligated to accept": a qualitative exploration of contraceptive coercion. Social Science \& Medicine, [s. l.], v. 239, p. 1-10, 2019.

SISTERSONG WOMEN OF COLOR REPRODUCTIVE HEALTH COLLECTIVE. Long-Acting Reversible Contraception: statement of principles. [S. l.]: SisterSong: National Women Health Network, 2016.

TAKESHITA, C. The global biopolitics of the IUD: how science constructs contraceptive users and women's bodies. Cambridge: MIT Press, 2012.

VALDEZ, N.; DEOMAMPO, D. Centering race and racism in reproduction. Medical Anthropology, [s. l.], v. 38, n. 7, p. 551-559, 2019.

VIANNA, A. Etnografando documentos: uma antropóloga em meio a processos judiciais. In: CASTILHO, S. R. R.; LIMA, A. C. S.; TEIXEIRA, C. C. (org.). Antropologia das práticas de poder: reflexões etnográficas entre burocratas, elites e corporações. Rio de Janeiro: Contra Capa, 2014. p. 43-70. 
VIANNA, A.; LOWENKRON, L. O duplo fazer do gênero e do Estado: interconexões, materialidades e linguagens. Cadernos Pagu, Campinas, n. 51, e175101, 2017.

WERNECK, J. Ou o belo ou o puro? Racismo, eugenia e novas (bio)tecnologias. In: ROTANIA, A. A.; WERNECK, J. P. (org.). Sob o signo das bios: vozes críticas da sociedade civil. Rio de Janeiro: E-papers, 2004. v. 1, p. 49-63.

WILLIAMS, S.; MARTIN, P.; GABE, J. The pharmaceuticalisation of society? A framework for analysis. Sociology of Health \& Illness, [s. l.], v. 33, n. 5, p. 710-725, 2011.

WORLD HEALTH ORGANIZATION. Department of Reproductive Health and Research. From evidence to policy: expanding access to family planning - strategies to increase use of long-acting and permanent contraception. Geneva: WHO, 2012.

Recebido: 18/10/2020 Aceito: 06/07/2021 | Received:10/18/2020 Accepted: 7/6/2021 